\title{
SISTEM TRANSAKSI BARANG RETAIL MENGGUNAKAN RFID
}

\author{
Oscar Yudha Senna \\ Jurusan Teknik Informatika Universitas Muhammadiyah Surakarta (UMS) \\ Surakarta, Indonesia oscarys@hexatekno.com \\ Heru Supriyono \\ Jurusan Teknik Elektro Universitas Muhammadiyah Surakarta (UMS) \\ Surakarta, Indonesia Heru.supriyono@ums.ac.id
}

\begin{abstract}
Abstraksi- Perkembangan teknologi saat ini telah berkembang sangatlah pesat. Terdapat banyak sekali alat alat yang dapat membantu menyelesaikan pekerjaan manusia, salah satunya adalah dengan teknologi Radio Frequency Identification (RFID). RFID dapat dimanfaatkan seperti pengelolaan data barang pada sebuah toko retail dan memudahkan transaksi kepada customer di sebuah toko. Pada kebanyakan toko khususnya toko retail seperti baju masih menggunakan cara manual menulis katalog dari item yang akan dijual dan transaksi juga menggunakan cara manual yang dinilai kurang cepat dan efisien. Untuk mengatasi masalah yang terjadi diperlukan sebuah sistem informasi secara komputerisasi agar masalah tersebut bisa diselesaikan lebih efisien cepat dan juga agar layanan yang diberikan ke konsumen juga bisa lebih efektif, cepat dan akurat. Tujuan dari dibuatnya sistem ini diharapkan supaya pengelolaan data dan sistem transaksi pada sebuah toko retail seperti baju dapat lebih baik. Sistem ini menggunakan teknologi RFID sebagai komponen utama dan dikaitkan pada price tag baju. Sistem ini dibuat menggunakan metode SDLC Waterfall dengan bahasa pemograman PHP dan MySQL sebagai database nya dan alat seperti RFID tag dan RFID reader. Hasil dari pengujian Sistem Aplikasi oleh pihak admin dan kasir menggunakan metode Blackbox sudah sesuai dengan tujuan program dibuat yaitu untuk membantu dalam melakukan pengelolaan dan transaksi agar dapat lebih efektif dan efisien dan perangkat RFID reader yang digunakan dalam sistem aplikasi dapat bekerja secara optimal dalam jarak maksimal 3-4 $\mathrm{cm}$ dan masih bisa bekerja meskipun antara reader dan tag terhalang dengan maksimal ketebalan penghalang $4 \mathrm{~cm}$ dan hasil pengujian kuesioner membuktikan bahwa sistem aplikasi ini layak untuk dipakai
\end{abstract}

\section{Katakunci-RFID; Toko Retail; PHP; MySQL}

\section{Pendahuluan}

Pengenalan Perkembangan teknologi saat ini sangat membantu pekerjaan manusia dalam bidang apapun. Radio Frequency Identification (RFID) merupakan salah satu teknologi yang telah berkembang secara pesat. RFID itu adalah teknologi yang mampu mengidentifikasi berbagai obyek secara stimultan tanpa diperlukan kontak langsung (contactless) dan tidak harus sejajar dengan obyek yang dibaca serta tidak diperlukannya jalur cahaya untuk dapat beroperasi, RFID dapat berfungsi pada berbagai variasi kondisi lingkungan dan menyediakan tingkat integritas data yang tinggi (Hamdani, 2015). RFID tag diklasifikasikan menjadi 2 kategori: yaitu tag pasif dan tag aktif. tag pasif tidak memiliki power supply khusus, power dari pasif tags berasal dari medan listrik yang dihasilkan oleh pembaca RFID (Wong \& Guo, 2014). RFID telah banyak digunakan dalam sebuah perusahaan, instansi dan tempat tempat yang lain. RFID ini sendiri menggunakan gelombang radio yang menggunakan frekuensi tertentu untuk dapat bekerja antara RFID reader dan RFID tag. Dari penelitian yang dilakukan oleh Rahardja, Frecilia \& Komaeni (2015), RFID memiliki dua komponen penting yang digunakan, yaitu tag yang berfungsi untuk menyimpan data jarak 
jauh dan reader untuk membaca data dari setiap tag dengan cara memancarkan gelombang radio dengan frekuensi tertentu.

Dengan adanya sistem yang berbasis RFID ini sangat memudahkan pekerjaan manusia yang berkaitan dengan input data barang ataupun identifikasi suatu item. Kemampuan RFID dalam mengidentifikasi suatu objek dapat digunakan untuk mengidentifikasi suatu item di toko retail. Pradipta, Mustika \& Sulestyo (2014) menjelaskan bahwa sebuah sistem pelayanan yang baik yaitu bagaimana customer dengan cepat dan mudah melakukan perbelanjaan. Biaya penerapan tag pasif relatif murah namun jarak efektif dari tag ke perangkat penerima gelombang radio juga terbatas untuk jarak dekat (Tanubrata, 2013). Karena pada toko ini transaksi tidak memerlukan jarak efektif yg jauh. Choi, Yang \& Yang (2015) menjelaskan bahwa perangkat RFID dipasang untuk meningkatkan kemudahan belanja customer dan preferensi, dimana akan sangat berguna untuk pemasaran dan meningkatkan bisnis retail. maka dari pertimbangan tersebut memungkinkan bahwa teknologi RFID untuk diimplementasikan kedalam sistem transaksi dan pengecekan barang pada toko retail.

Toko merupakan sebuah tempat yang dimana terjadinya kegiatan perdagangan dengan jenis benda atau barang yang khusus. Sebuah item yang didata secara manual ditulis dapat menimbulkan masalah jika tidak dikelola dengan baik dan dinilai kurang efektif. Selain itu sistem transaksi yang manual kurang cepat dan kurang mudah.

SB Hijab merupakan sebuah toko fashion yang awal mulanya toko online saja di suatu media social yang pada akhirnya juga melayani transaksi di tempat yang berada di Solo Baru, Jawa Tengah, Sukoharjo. Toko ini menjual beberapa jenis pakaian muslim wanita. Selama ini SB Hijab masih mencatat barang secara manual tertulis di buku untuk data katalog seperti harga, nama dan ukuran nya. Sedangkan untuk transaksi juga masih manual dengan menggunakan kertas nota dan kalkulator untuk menghitung total belanjaan. Apabila toko ini mendapatkan pembeli yang banyak akan kewalahan menanganinya. disitulah muncul permasalahan tentang kurang efektif nya dalam pencarian barang dan transaksi karena waktu yang digunakan relatif lebih lama dibanding dengan sistem komputerisasi. Supriyono, Noviandri \& Purnomo (2017) Menjelaskan bahwa data aset bisa dimasukkan dalam tag RFID yang ditempelkan pada barang/aset yang dimaksud yang kemudian data ini dapat dibaca dengan menggunakan RFID reader yang terhubung dengan computer melalui port USB.

Berdasarkan permasalahan di toko SB Hijab ini, penulis memiliki gagasan untuk mengimplementasikan teknologi RFID pada sistem transaksi sekaligus pengelolaan data item barang. Dengan adanya sistem ini diharapkan dapat membantu penjual dalam melakukan pengelolaan toko dan transaksi di toko, sehingga dapat lebih dilakukan dengan efektif dan efisien.

\section{DASAR TEORI DAN TinJauAn PUSTAKa}

Teknologi yang dipakai dalam sistem aplikasi ini yakni menggunakan teknologi RFID. Radio frequency identification (RFID) adalah sebuah teknologi yang menggunakan komunikasi via gelombang elektromagnetik untuk merubah data antara terminal dengan suatu objek seperti produk barang, hewan, ataupun manusia dengan tujuan untuk identifikasi dan penelusuran jejak melalui penggunaan suatu piranti yang bernama RFID tag. RFID tag dapat bersifat aktif atau pasif, pada sistem ini RFID tag yang digunakan merupakan RFID tag yang bersifat pasif.

\section{Metode PenELITIAN}

Metode yang digunakan untuk membuat sistem transaksi barang retail berbasis RFID ini adalah menggunakan metode system development life cycle (SDLC) Waterfall, yang terdiri dari tahap : (a) Analisa kebutuhan. (b) Desain sistem. (c) Penulisan Code Sistem Aplikasi. (d) Pengujian Sistem Aplikasi. (e) Penerapan Sistem Aplikasi. Sebagai mana gambar 1. 


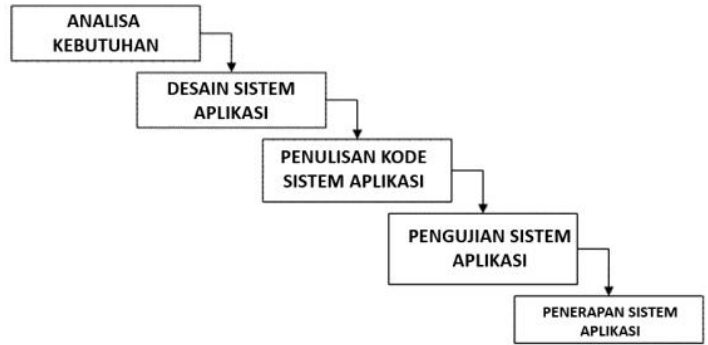

Gambar 1. Metode SDLC Waterfall

\section{HASIL DAN PEMBAHASAN}

\section{A. Eksperimen penetapan nilai numerik untuk penapisan warna}

Hasil dari sistem yang dibuat ini menghasilkan sebuah sistem transaksi jual beli barang, pengelolaan item yang dijual dan juga rekap secara komputerisasi. sistem ini berisi data data seperti item yang dijual, anggota user, dan juga data record transaksi. Sistem memiliki dua hak akses sesuai dengan status yang sudah disimpan dalam database dimana nanti user dapat masuk ke halaman utama sistem sesuai dengan hak aksesnya.

Halaman awal merupakan halaman form login yang mengharuskan user memasukkan nomor hp dan password yang sesuai dengan data yang telah dimasukkan dalam database. Gambar form login dapat dilihat pada gambar 7.

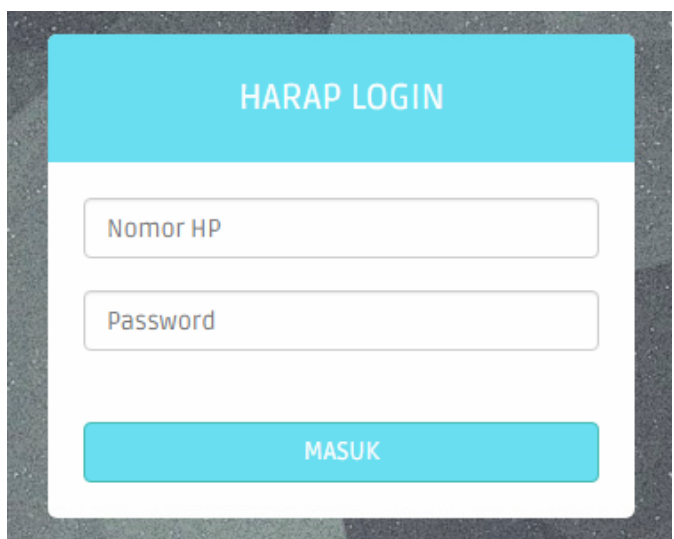

Gambar 7. Halaman form login

Gambar 8 merupakan halaman utama sistem untuk hak akses admin, pada sidebar terdapat menu Pengelolaan item untuk melihat, menambah dan menghapus item, Keanggotaan untuk melihat, menambah dan menghapus anggota user, Data Transaksi untuk melihat semua transaksi yang dilakukan dan Rekap untuk melakukan print rekap berdasarkan tanggal dan berdasarkan sebuah item, dan pada header sebelah kanan terdapat menu logout untuk melakukan aksi logout.

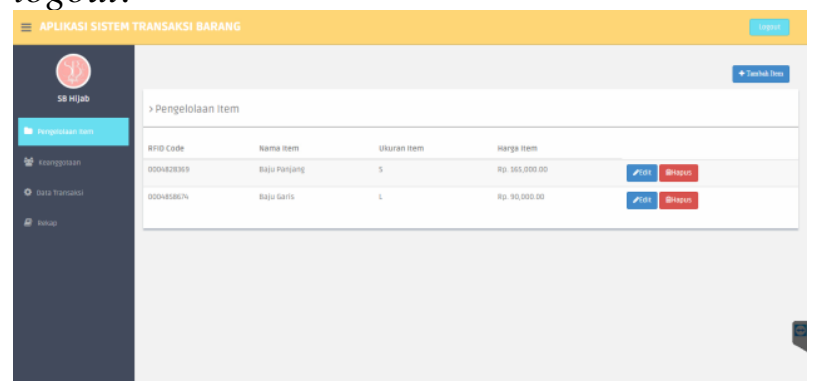

Gambar 8. Halaman Utama pada Hak Akses Admin

Pada Gambar 9 merupakan halaman utama sistem untuk hak akses kasir, pada sidebar terdapat menu Transaksi untuk melakukan transaksi jual beli, Data Transaksi untuk melihat semua transaksi yang dilakukan dan pada header sebelah kanan terdapat menu logout untuk melakukan aksi logout.

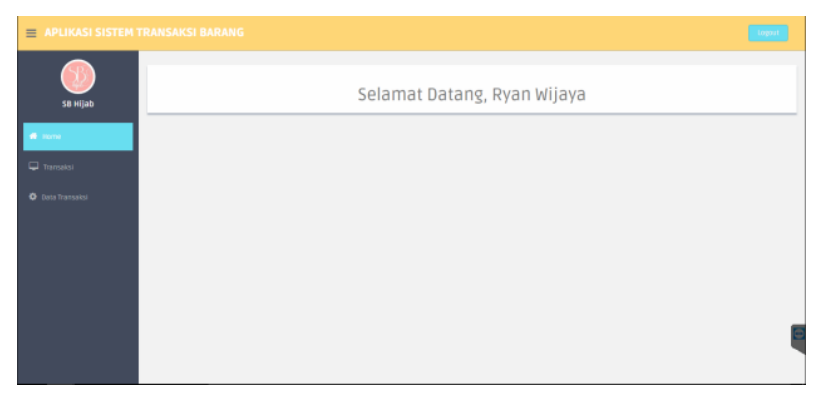

Gambar 9. Halaman Utama pada Hak Akses Kasir

Dan pada halaman sistem untuk hak akses Kasir, pada sidebar terdapat menu home sebagai halaman pembuka, Transaksi untuk melakukan aksi transaksi jual beli, dan Data Transaksi untuk melihat semua transaksi yang dilakukan.

Sistem transaksi pada aplikasi ini menggunakan RFID yang dimana RFID tags dikaitkan pada barang item untuk menampilkan nama, ukuran, dan harga pada item tersebut, sehingga transaksi yang dilakukan akan lebih mudah dan cepat dimana sangat membantu kasir dalam 
transaksi penjualan. Halaman Transaksi dapat dilihat pada Gambar 10.

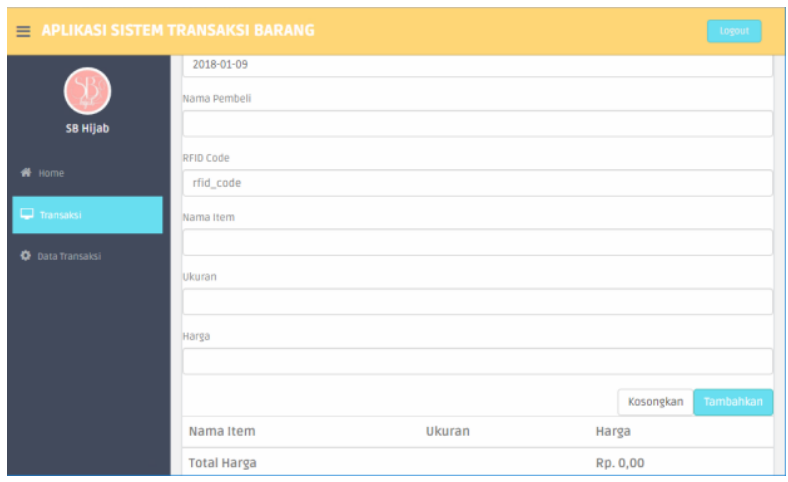

Gambar 10. Halaman Transaksi Penjualan

Dalam proses transaksi, RFID reader digunakan sebagai alat pembaca dari RFID tags dimana bila RFID tags di scan dengan RFID reader maka akan langsung muncul item yang dimaksud. Gambar 11 adalah merupakan script untuk menampilkan detail item yang ada pada tags RFID tersebut.

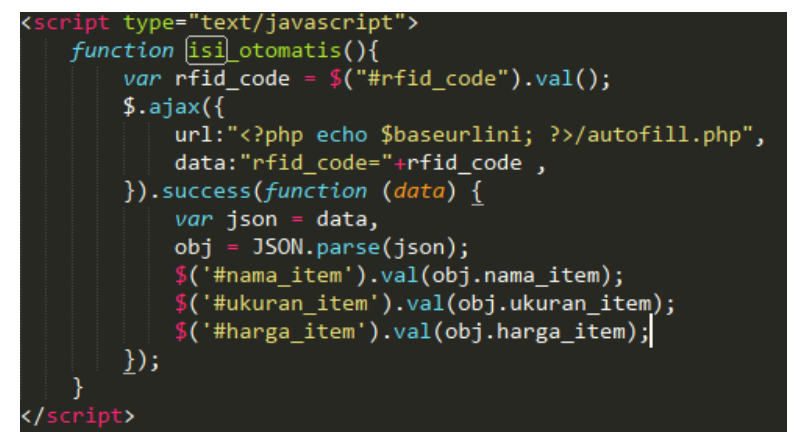

Gambar 11. Script untuk menampilkan detail item

Proses transaksi yang telah dilakukan akan otomatis tersimpan ke dalam database, jadi admin dan kasir dapat melihat, mencari transaksi tertentu. Fitur ini dapat membantu kasir maupun admin dalam mengecek transaksi yang dilakukan, data yang ditampilkan pada fitur pencarian pada data transaksi ini yaitu ID transaksi, Tanggal, RFID code, Nama Kasir, Nama Pembeli, Item yang dibeli dan Nominal. Untuk halaman Data Transaksi bisa dilihat pada Gambar 12.

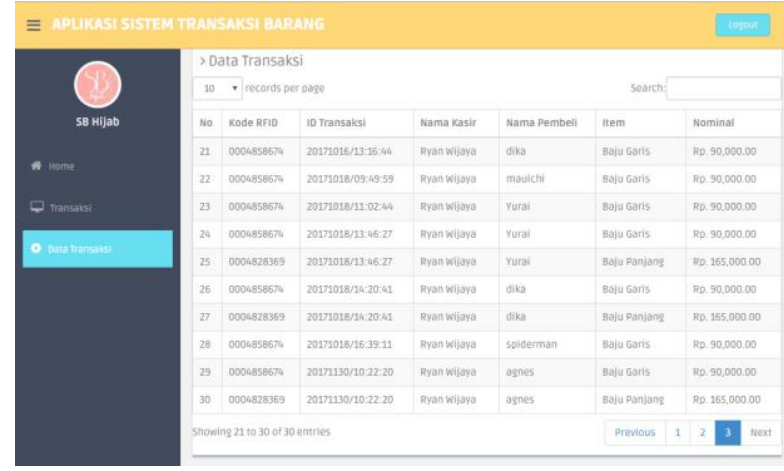

Gambar 12. Halaman Data Transaksi

Pada menu rekap data, petugas (Admin) dimudahkan dalam membuat rekap data penjualan bulanan ataupun tahunan pada item tertentu ataupun seluruh item yang terjual. Karena sistem ini bekerja secara offline maka laporan rekap dapat dicetak langsung dalam bentuk pdf menggunakan fitur pada office dengan ekstensi Microsoft Print to PDF yang terdapat pada browser. Hasil laporan rekap dalam bentuk PDF dapat dilihat pada gambar 13.

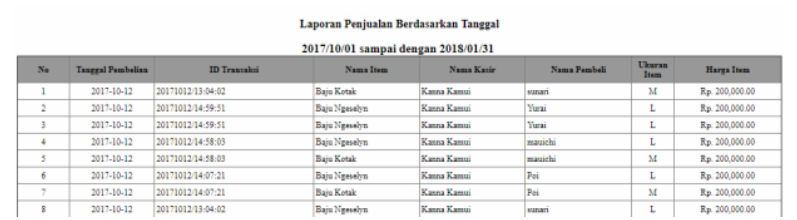

Gambar 13. Halaman Hasil Cetak Rekap

Data yang ditampilkan pada Hasil rekap tersebut adalah merupakan hasil query dari gambar 14 .

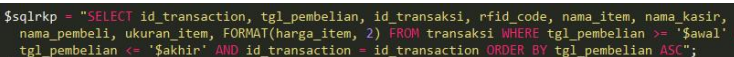

Gambar 14. Query untuk menampilkan data pada rekap

Aplikasi Sistem Transaksi ini telah diterapkan pada toko dengan menggunakan perangkat laptop. Selain itu beberapa R FID tags juga sudah dikaitkan pada item item. Pada Gambar 15 berikut adalah hasil sistem yang telah diterapkan pada toko dan juga Gambar 16 merupakan RFID tags yang ditempelkan pada item. 


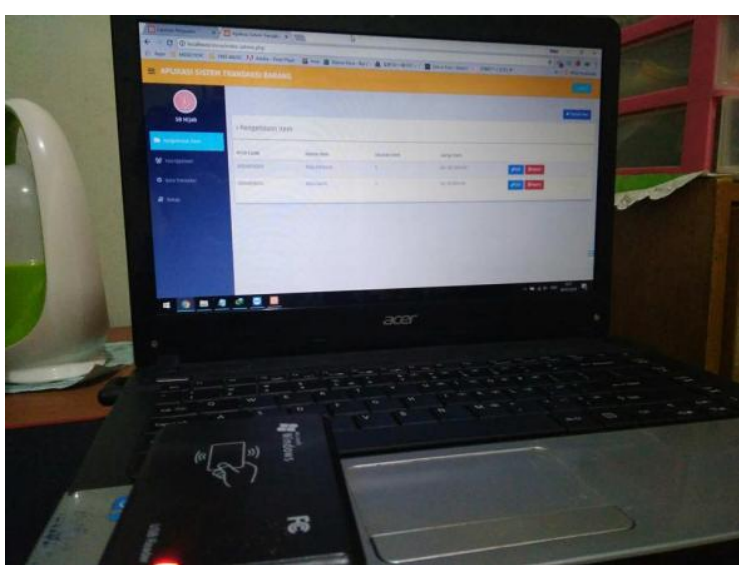

Gambar 15 . RFID reader sudah di pasang pada laptop

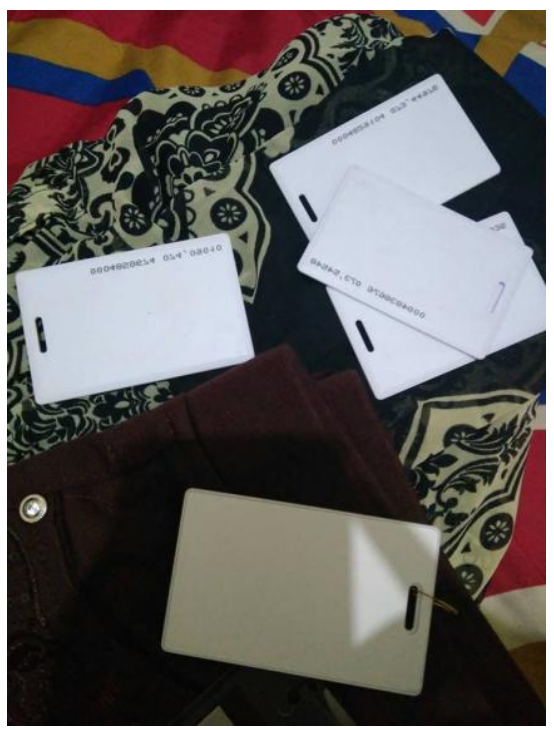

Gambar 16. RFID tags sudah di kaitkan pada item

\section{KESIMPULAN}

Berdasarkan dari perancangan dan pembuatan sistem transaksi dan pengelolaan item dengan menggunakan RFID dapat disimpulkan sebagai berikut (1) Proses transaksi dan pengelolaan barang dengan memanfaatkan sistem RFID dapat berjalan dengan lebih efektif dan efisien dan proses rekap dari data penjualan menjadi lebih mudah, Jadi sistem bekerja sesuai dengan tujuan utama penelitian, (2) Perangkat RFID reader yang digunakan dalam sistem aplikasi dapat bekerja secara optimal dalam jarak maksimal 3-4 cm dan masih bisa bekerja meskipun antara reader dan tag terhalang dengan maksimal ketebalan penghalang 4 $\mathrm{cm}$, dan (3) hasil pengujian kuesioner membuktikan bahwa sistem aplikasi ini layak untuk dipakai.

\section{Daftar Pustaka}

[1] Choi, S.H., Yang, Y.X., Yang, B. \& Cheung H.H.' (2015). Item-level RFID for enhancement of customer shopping experience in apparel retail, The 10.1016/3.compind.2015.03.003, 10-23.

[2] Hamdani, F. (2014). Penerapan RFID (Radio Frequency Identification) Di Perpustakaan: Kelebihan dan Kekurangannya, Khizanah Al-Hikmah, 2(1), ISSN: 2354-9629, 71-79.

[3] Pradipta, G.A, Mustika I.W \& Sulestyo, S (2014). Sistem Check Out Kasir Pada Supermarket Grosir Dengan Menggunakan Passive RFID Technology, Seminar Nasional Teknologi Informasi dan Komunikasi, ISSN: 2089-9813, 2834.

[4] Rahardja, U., Frecilia, Y. \& Komaeni, N. (2015). Analisa Peminjaman Buku Perpustakaan Dengan Menggunakan Sistem. RFID Pada Perguruan Tinggi Rahardja, Journal Creative Communication and Innovative Technology, 9(1), ISSN: 1978 -8282, 112.

[5] Supriyono, H. Noviandri, A.M. \& Purnomo, Y.E.'(2017). Penerapan Sistem Informasi Berbasis Komputer Untuk Pengelolaan Aset Bagi SMP Muhammadiyah 1 Kartasura, The 6 Universty Research Colloquium, ISSN: 2407-9189, 59-70.

[6] Tanubrata, M. (2013). Penggunaan RFID Untuk Mendukung Otomasi Perhitungan Biaya Simpan Dan Transit Barang Produksi Di Pabrik, Simposium Nasional RAPI XII, ISSN: 1412-9612, 15-21.

[7] Wong, W.K \& Guo Z.X. (2014). Fashion Supply Chain Management Using Radio Frequency Identification (RFID) Technologies, Woodhead Publishing Limited in association with The Textile Institute 10.1533/9780857098115.1, 4-6. 